\title{
BENEFITS AND BURDENS: RESEARCHING THE CONSEQUENCES OF MIGRATION IN THE SAHEL
}

\section{Orlanda Ruthven and Rosalind David}

\section{INTRODUCTION'}

This article is based on recently completed research conducted by SOS Sahel. The research ${ }^{2}$ examined the consequences of rural out-migration for women and natural resource management at four sites in the Sahel: Passoré in Burkina Faso, Diourbel in Senegal, El Ain in Sudan and Bankass in Mali. While issues of gender roles and activities have been among the preoccupations of this study, these have been used to respond to the broader policy concerns of IFAD and SOS Sahel.

The two major concerns shared by IFAD and SOS Sahel were as follows: First, the rural out-migration of (mostly) men to urban and commercial centres is becoming increasingly widespread, but the nature of migration and the impact on rural livelihoods are not understood clearly. The idea that rural male outmigration directly increases the vulnerability of remaining women was thought plausible, but was unsubstantiated. Second, both organizations were attempting to integrate women into their resource management programmes and it was felt that a greater understanding of women's farming practices was needed in order to integrate them more effectively.

The research has not addressed questions about changing gender relations which a gender analysis might have posed. However, it does show that the impact of migration on women's management of natural resources varies considerably depending on prevailing gender divisions and relations of labour, of land access and control, and of responsibilities towards family and personal production.

\section{THE CASE STUDIES AND THE CONTEXT OF MIGRATION}

All four research areas are characterized by predominantly settled populations and rainfed agriculture, are subject to environmental degradation and prone to high levels of male out-migration.

\section{Diourbel (Senegal)}

The region of Diourbel lies in the heart of the Senegalese Groundnut Basin and is one of the most densely populated regions of the Sahel. The area has an average population density of 113 people per $\mathrm{km}^{2}$, has experienced declining rainfall and has little potential for agricultural expansion. High levels of seasonal male out-migration are apparent. Approximately 70 per cent of local men migrate mainly to Dakar to find dry season job opportunities and in some villages it is difficult to find any able-bodied men during this period.

\section{Passoré (Burkina Faso)}

The province of Passoré lies in the Central Plateau of Burkina Faso. The region receives variable (500-700 $\mathrm{mm}$ ) and declining rainfall and has fragile and infertile soils. The population density is relatively high at 55 people per $\mathrm{km}^{2}$, although lower than Diourbel. Declining soil fertility has led to falling agricultural productivity. Declining harvests, diminishing herds, changing cash needs and a lack of alternative income opportunities in the region have precipitated male out-migration. Migrants from this region leave for much longer periods than those from Diourbel: an average migration lasts for seven years for 74 per cent of the sample, with most migrants working in the Ivory Coast.

\section{Bankass (Mali)}

Rainfall in Bankass is unpredictable, varying from as little as $225 \mathrm{~mm}$ in a 'bad' year to over $700 \mathrm{~mm}$ in a 'good' year. The population density in the study area is 37 persons per $\mathrm{km}^{2}$. Soil fertility has declined as a result of the trend to lower rainfall, the decrease in vegetative cover and resulting erosion from wind and rain. Out-migration from this region is increasing as young girls as well as adult and young men feel the pressure to acquire a cash income. While approximately half the migrants leaving Bankass are seasonal and return to help in the fields during the rainy period, half are longer-term, staying away for
${ }^{1}$ Copies of the full report of this research can be obtained from SOS Sahel: 1, Tolpuddle St, London, N1 OXT, Tel: 0718379129
2 The research was co-funded by the International Fund for Agricultural Development and the ESRC's Global Environmental Change Programme. 
many years at a time. Most migrants travel to Abidjan in the Ivory Coast and, increasingly, to the cities of southern Mali.

\section{El Ain (Sudan)}

Of the four study areas, El Ain Forest, Kordofan is the least populated, with approximately 12 people per $\mathrm{km}^{2}$. Until the 1960s Kordofan province was not only self sufficient in foodstuffs but also produced agricultural surpluses, especially gum arabic and livestock, for sale. Over the last thirty years, grain production has fallen by a third. Declining rainfall and the over-exploitation of trees has put an end to gum arabic production from Acacia senegal whilst the severe droughts of the early 1970s and 1980s killed large numbers of livestock. As agricultural productivity falls and alternative cash opportunities diminish, local people are forced to look elsewhere for ways of maintaining their livelihoods. Seasonal out-migration to other rural locations to seek paid agricultural employment and to urban areas such as Khartoum is a long-standing tradition in this region.

\section{THE RATIONALE OF THE RESEARCH}

The literature dealing with the consequences of migration has generated a range of context-specific hypotheses. These give an indication of the character of women's farming, and of the relationship between urban (or commercial) and rural livelihoods. The scenarios commonly suggest a negative relationship: that rural-urban migration is at best incompatible with, and at worst, detrimental to, the on-farm and subsistence activities of villages.

i Gisbert et al. (1992) argue for Bolivia that labour shortages resulting from male out-migration impede women's effective environmental management. The emphasis is placed on increased work burdens which limit women's capacity to manage effectively agricultural and herding activities.

ii O'Keefe and Wisner's (1977) study of Kenya suggests that men's out-migration discourages women from carrying out labour-intensive investments such as terracing on farm land. No longer able to ensure the sustainability of their farming, men and women in the village prioritize short-term, over longer-term production goals.

iii Monimart (1989) and Smale (1980) suggest, for marginal, rural areas of the Sahel, that the out- migration of men makes it difficult for women remaining in villages to subsist. Eventually, some women are forced to follow their husbands to commercial centres.

In the above scenarios, male out-migration is portrayed as ultimately jeopardizing rural livelihoods: farm management deteriorates and subsistence for women and others in the village becomes difficult or impossible. Area-specific studies are often decontextualized by policy makers and their findings applied to a range of situations. This article questions the usefulness and applicability of these general models of the impact of migration.

In this article, a brief overview of the effects of migration in four Sahelian locations is presented. Three general issues arise out of the research. First, migration, far from being disastrous for rural life and for women, appears to be a rational means through which families sustain their rural livelihoods. Second, the relationship between migration and the well-being of the rural environment is far more remote than is often suggested: the cause-effect relation posited between environmental management and migration tends to be ambiguous. Third, the case studies indicate that women manage to sustain, or even increase, their inputs to cultivation in response to men's migration. To this end, the case studies question the assumed relationships between rural and urban livelihoods and between women and natural resource management.

\section{THE RESEARCH FINDINGS}

\subsection{Remittances and cash security}

This research is focused primarily on the relationship between migration and women's farmland management, although this can not be assessed separately from the more immediate consequences of labour migration. The incentive to migrate is twofold. On the one hand, farmers in the Sahel, facing a trend of semi-drought years, cannot afford to rely wholly on agriculture. On the other hand requirements for cash among these populations have been increasing steadily in recent years. These two processes are closely linked.

In all case studies except the Bankass region in Mali, out-migration by men is a response to concerns about food security. Migration eases the pressure on household food supply through the dry season. 
Men are usually able to acquire a cash income, albeit small, with which to purchase food, thereby making up the deficit between food produced and consumed in the family. However, it is not only the recent trend of low rainfall which has encouraged farmers to buy food. The cheap price of imported food, particularly in Senegal (prior to the devaluation of the FCFA in January 1994), and the poor terms of trade between agricultural and manufactured goods, have also encouraged this. Migration then, is a means by which families spread their risks and ensure some cash support in times of harvest failure. In the Bankass region, higher land fertility combined with less population pressure means that most people are able to grow enough food for their requirements. Agriculture remains a relatively productive and secure livelihood, and, unlike the other study areas, Dogon people tend to invest a large proportion of their cash income in agricultural equipment such as carts, traction animals and livestock to provide manure.

The importance of non-cash remittances for families everywhere should not be underestimated. For young, male migrants and their female relatives, imported items brought back from urban centres carry prestige and are highly valued. The wives of migrants may consider their husbands' gifts of modern kitchenware and imported clothing more important than the small sums of 'pocket money' which may also be received. Young migrants frequently spend most or all of their earned money while they are away, and return with consumer goods such as cassette players and sunglasses. The cash requirements of rural Sahelians are expanding continually, as they are simultaneously fuelled and quenched by migration. Ideas of 'essential' needs have changed, and within the last generation, have come to include many new additions, such as plastic sandals, rice, medicines and school fees.

If migration illustrates the preference felt by many villagers for cash-earning, urban strategies over agriculture, how are agricultural livelihoods, and in particular, the resource management of women, affected as a result? The case studies show that the impact of migration on women's farmland management depends on three factors. Firstly to what extent the migration of men has resulted in a lack of labour at village level. Second, it depends, partly, on the character of farmland management in the region prior to, or in the absence of, migration and to what extent activities aimed at improving soil fertility are being carried out. Third, the roles of women in the management of farmland, in maintaining soil fertility, and, more generally, in substituting for absent male labour by carrying out conventionally 'male' tasks are all important.

\subsection{The shortage of labour}

In three of the case studies (El Ain in Sudan, Bankass in Mali and Passoré in Burkina Faso), both male and female farmers complained that they suffered from labour shortages on their farms. In many cases, this was seen to result directly from the out-migration of men. In these three cases, agriculture is overwhelmingly performed by hand with only very limited use of animal traction and ploughs.

In Sudan, where land is widely available and cultivation very extensive, labour to cultivate land has always been scarce. As increasing numbers of men leave rural areas for longer periods and are absent during the farming season, this labour scarcity has taken on a new dimension. In Passoré and Bankass, labour, rather than land, has also historically been the main constraint on agriculture. Labour shortages are felt more potently on less intensively cultivated fields some distance from the village, where fewer people have a claim to the land or a responsibility to cultivate it.

In Passoré, increased incidence of long-term migration has paralleled a decline in the availability of good land. As farmers seek to sustain their harvest yields and rehabilitate tired soil, the labour shortage is increasingly felt. Among the Dogon in Mali, migration has exacerbated traditional labour shortages as young men prioritize their commitment to urban life over their responsibilities towards their families. Unlike the dry season off-farm activities undertaken by men in the past, these contemporary migrations frequently endure through some or all of the farming season. Young migrants often return home for only two or three weeks in a year and thus cannot be relied upon to contribute agricultural labour.

In Diourbel, Senegal, farming is mechanized and the majority of tasks are performed using ploughs and traction animals. Thus a lack of labour is not usually felt in spite of migration. However, an important issue in this area is to what extent mechanization has affected the gender division of labour in rural farming systems. 


\subsection{Farmland management in the study areas}

The contemporary state of soil management in each of the case studies reflects the different histories of the regions. While two of the study areas (the Mossi region of Passoré in Burkina Faso and the Dogon region of Bankass in Mali) have sustained traditions of investing in and conserving their farmland, this is not the case in Diourbel (Senegal) nor in El Ain (Sudan).

Dogon resource use has been shaped over several centuries by a concern to maximize security in the face of a hostile political environment. Building their villages along the Bandiagara Escarpment, Dogon farmers developed farming techniques which enabled the exploitation of an area of land as close possible to the Escarpment. While the changes of the twentieth century have enabled Dogon settlements to spread out onto the Seno-Gondo plains, they have kept up their intensive and regenerative cultivation techniques. In contrast, in Mossi society, which was historically warfaring, land management focused primarily on restricting the exploitation of certain trees and practising fallow. Over the last thirty years, in response to changes caused by drought and population growth, Mossi communities have resorted to large-scale permanent out-migration, or haveevolved a range of techniques aimed at regenerating their increasingly degraded farmland and intensifying their agriculture.

In Diourbel (Senegal), recent and dramatic environmental and political changes have caused the neglect of many of the land improvement techniques practised in the past. The Serere people practised agrosylvo pastoralism until the early twentieth century. The combined influence of the Islamic movement of Mouridism, the rapid growth of the region's Wolof population and the development policies of the colonial government, encouraged the emergence of a commercialized groundnut sector. The Serere and the Wolof prioritized the production of this cash crop at the expense of agroforestry and pastoralism. Mulching practices, mixed cropping and fallow also disappeared and reliance on subsistence production declined dramatically. As the population grew rapidly and the government subsidized basic technologies such as ploughs and chemical fertilisers, the people of Diourbel expanded onto ever more marginal land. Today, the range of techniques utilized to improve soil fertility is vastly reduced as people prioritize their capacity to acquire cash over food production.
Land tenure and management in El Ain (Sudan) must be seen in the wider context of policy changes at the regional and national levels. Sudan has experienced a profoundly unsettled period of rural administration since 1969, in which the system has changed twice (first removing and then reinstating the traditional rural hierarchy); the resulting state of confusion over responsibility for land and its management has caused considerable damage. Despite increasing deforestation caused by drought and human activity, measures to manage and improve renewable natural resources are limited. People continue to cultivate at low yields. Because most families have larger holdings than they have labour available to cultivate, whether by omission or design, land is regularly fallowed. Thus, people feel no express need to combat erosion or improve the land.

\subsection{Women's role in farmland management}

As a source of labour to their husband and his lineage and as cultivators of their own plots, women throughout the Sahel play a prominent role in agriculture. In the West African case studies, women marry into their husbands' families. These are usually based on patrilineages descended from the original ancestor-settlers of the village or region. By virtue of this genealogical connection, a man acquires access to and sometimes the custodianship of land and its produce from his family. In addition, men acquire rights to land through clearance, which they may cultivate for their immediate families and hand down to their offspring. As lineage wives, women are a crucial source of labour and will, in return, be given access to the produce of family fields. Through their husbands, women also acquire access to their own plots of land on which they will grow vegetables and / or secondary crops. These crops may be sold or used to make sauce to accompany the staple meal of their households.

For Mossi women, work on family fields is a priority obligation. Together with men, women carry out a range of long and short term investment techniques to sustain yields on these fields. These include stone bund construction; tree and hedge planting; digging planting-pockets; grass planting (Andropogon gayanus); applying manure, waste and compost to farmland and mulching with leaves and stalks. Once they have fulfilled their obligations on family fields, women cultivate their personal plots. As lineage members, men control a greater proportion of agricultural produce than women (mostly in the form of grain). However, their responsibility to provide 
grain to their extended families and their immediate households constrains the ways in which this produce can be used.

The differential tenure rights of men and women have an impact on the management of family and women's plots. The techniques employed on women's plots tend to be shorter-term and, reflecting their more general marginalization from productive resources, women are unable to claim scarce and valuable inputs, such as manure, for this land. These inputs are applied more or less exclusively to family fields. However, women use household waste on their plots which they say they can acquire more easily. Moreover, they tend to construct mainly earth, rather than stone bunds.

An IFAD project has introduced a tree-planting scheme in the region but to date this has worked exclusively with men. Women report that they have not considered planting trees on their own land. It is clear that such longer-term investments are associated with men as the custodians of the land.

Women report that they have had to compensate for a shortage of male labour on family fields in the light of men's migration. They thus contribute more labour to the soil improvement techniques used on family land. In consequence, their personal plots, as well as those of men, receive correspondingly less labour input. While farmers may respond to labour shortfalls by decreasing the area they cultivate, both women and men are more likely to cultivate the same area but less intensively with resultant decreasing yields and less effective soil maintenance. However, women's prioritization of family land means that these fields probably receive the same degree of soil improvement as they did prior to the male labour shortage. In short, although there appears to be little evidence of a more general decline in long-term soil management on family farms, the intensiveness of soil management is sustained only at the expense of women's work on their own plots, and so risks jeopardizing a major source of security for themselves and their children.

Among the Dogon of Mali, women's farming activities are largely confined to their personal plots of groundnuts and groundpeas (vouandzou) which, under the prevailing gender division of labour, they are able to prioritize. Although women help men and children regularly in the family fields, they have no formal responsibility to do so. Families apparently allow their wives to work their own plots for an average of three days a week throughout the farming season. This means that women's workload is much less directly affected by the out-migration of men. However, to cultivate their personal plots, women rely heavily on the support of their unmarried children. As members of their father's lineage, these children must prioritize work on family fields and household fields managed by their father. Serious shortages of male labour are filled by these children rather than their mothers. However, in consequence adult women may suffer a labour shortage on their own plots.

Because of the nature of the crops they plant, the techniques employed by Dogon women tend to be less strenuous than the intensive weeding required for grain cultivation. However, cultivation on women's plots is manual, and for much of the farming period a woman may not be able to enlist others to help her. The preparatory activities of clearing fallow land and constructing terraces are male activities from which women benefit. Like men, women practise fallow, allow Andropogon gayanus grass to grow on the borders of their plots, and protect, rather than plant, naturally regenerating trees. However, they do not ap ply manure to their plots as the men do. Like Mossi women, Dogon women have access to household waste for their plots. So, while women undertake both shorter- and longer-term investment techniques, they do not replace male labour directly. Labour shortfalls are filled by unmarried children and older men. As a result, while family fields are probably cultivated as intensively as ever, women's plots and household plots may occasionally lose out as children prioritize work on family fields.

As mentioned previously, in Diourbel (Senegal), agriculture is increasingly nolonger the most important source of income. In a society where the commercialization of agriculture preceded the high incidence of male out-migration, it is less easy to assess how migration, as distinct from these longerterm changes, has affected farmland management. Serere and Wolof women are responsible for manual tasks (for example, the weeding of millet and groundnuts, winnowing, manual sowing, and the harvesting of groundnuts and vegetables) on family, their husbands' and their own fields. They do not work the machinery and traction animals which dominate farming; these tasks are reserved for men and young boys. As in the other West African case studies, women are allocated their own plots by 
their husbands, but this occurs every year and thus women do not appear to develop the same attachment to their land, as in Bankass and Passoré where women may cultivate the same area for a number of consecutive years. Importantly, very few farmers in Diourbel practise fallow. Like men, women apply household waste and practise rotation cropping on their plots. However, whereas manure and sometimes chemical fertilizers are applied on family fields, women's plots tend not to receive these inputs.

These fertility-maintaining techniques tend to involve male tasks and inputs which are difficult for women to control for themselves. The application of manure, for example, involves transporting the inputs by horse, donkey or cart. In the absence of men, women are dependent on the labour of male child ren or neighbours, or, occasionally, hired itinerant labourers, to carry out these tasks. Because fertiliser purchase is a male activity, the presence of men is likely to increase fertiliser use, in those instances where households can still afford this input. Furthermore, as the custodians of the land, and thus the target group of the local IFAD project, men rather than women are involved with agroforestry.

In the light of male out-migration, women may spend more time helping men and boys on family and even their husbands' plots at the expense of their own. However, because most women prioritize offfarm commercial activity anyway, this reduction in labour input is of less importance than among Mossi or Dogon women whose livelihoods are more dependent on on-farm activity. Perhaps more important is the fact that the timing of particular 'male' tasks on all farmland, where machinery and traction animals are involved, may suffer, and production fall, since women have not replaced male labour for these tasks.

In El Ain (Sudan), the gender division of labour is much less distinct. Men and women work together on family plots where grain and cash crops are cultivated, and women also cultivate vegetables and other secondary crops (predominantly okra) on their garden plots (jubarik). Farming is unmechanized and the quantity of inputs, such as manure, is extremely low. Farming is based on mixed cropping and many men and women acquire some manure for their plots. However, due to the recent droughts, livestock herds, and thus the availability of manure, has been hugely reduced. On family plots, rotation fallow is practised, and Acacia senegal are left to grow during fallow periods. In contrast, women's plots are cultivated continuously. Women are said to hinder the process of natural regeneration of trees by cutting green wood to use as dry fencing for their plots.

Overall, in El Ain intensive on-plot investments are not prioritized but where they arecarried out, women are key participants. For women whose husbands are absent through the farming season, their burden of work does increase, since they are forced to take responsibility for cutting and clearing crops, as well as for marketing.

There is some evidence in all the West African studies that through migration, communities postpone their commitment to more intensive and rehabilitative activities on the land, although there is little evidence of a more general decline in long-term environmental management in these areas. Where migration is longer-term (above all, in Passoré), women fill the male labour gap. This may increase their work burden and reduce the productivity of their independent fields, the source of their security. In this respect, women are sacrificing autonomy in production and provisioning, while becoming more tied to and responsible for family fields. On the other hand, it ensures that much of the longer-term on-plot investments are still carried out, at least on family land. In spite of the disadvantages, particularly in Passoré, there appears to be a consensus that men migrate for the good of their families. Only in exceptional circumstances are they viewed as having deserted them. Women's tendency to reproduce the same view is perhaps reflected in the way migrants are able to retain their decision making and political roles as men of the village community. However, this would seem to suggest that men's out-migration is not strongly challenging gender roles in decision making and the notions of the family in which these are embedded. This is an interesting question which merits further research.

\section{CONCLUSION}

It has been shown that, in contrast to some of the 'pessimistic' scenarios presented in the literature, migration does not necessarily lead to the increased vulnerability of women nor to increased environmental degradation. The findings of the research show that the relationships which exist between migration, environmental management and women's security, are complex and specific to a particular regional context and this requires an analysis of the 
particular gender division of labour and rights of access to and control over productive resources in specific contexts. The tendency of development agencies to produce general models which articulate the cause-effect relations between these issues is far more likely to hinder, rather than facilitate, development initiatives.

Whereas in the development sector, migration is often approached as a unified, economic process, in this research it appears more as a collective term for a diversity of strategies with different historical roots and consequences. Contrary to many pessimistic scenarios, migration can be an effective response to rapid and detrimental changes in the rural environment.
It is clear that some women face an increased workload in the absence of their male relatives. Furthermore, they may be obliged to give preference to activities where they have little control over the product. On the other hand, women, as much as men, appreciate the need for a source of cash, and, in the light of a bad harvest, the need to move away from the village so as to ease pressure on food supplies. In coping with migration, rural people demonstrate that, far from being engaged in a transition from rural and subsistence, to urban and commercial living, they have created a means through which they can sustain and facilitate their farming lives in the village, although not one without gendered costs.

\section{REFERENCES}

Gisbert, M., Painter, M. and Quiton, M., 1992, 'Women's work in areas of high male out-migration', Development Anthropology Network Vol 10 No 2, Binghampton, NY: Institute of Development Anthropology

Monimart, M., 1989, Femmes du Sahel: La Desertification au Quotidien, Paris: OECD/Club du Sahel
O'Keefe, P. and Wisner, B., 1977, Land Use and Development, London: International African Institute

Smale, M., 1980, Women in Mauritania: The Effects of Drought and Migration on their Economic Status and Implications for Development Programmes, Washington DC: USAID, Office for Women in Development 